УДК 332.142.2

DOI 10.18413/2687-0932-2020-47-2-288-294

\title{
ФОРМИРОВАНИЕ УСЛОВИЙ ИННОВАЦИОННОГО РАЗВИТИЯ ЭКОНОМИКИ РЕГИОНА
}

\section{FORMATION OF THE CONDITIONS OF INNOVATIVE DEVELOPMENT OF THE ECONOMY OF THE REGION}

\author{
Парфенова Е.Н. ${ }^{1}$, Авилова Ж.Н. ${ }^{2}$ \\ Parfenova E.N. ${ }^{1}$, Avilova Zh.N. ${ }^{2}$ \\ 1) Белгородский государственный национальный исследовательский университет, \\ Россия, 308015, г. Белгород, ул. Победы, 85 \\ 2) Белгородский государстенный технологический университет им. В.Г. Шухова, \\ Россия, 308012, г. Белгород, ул. Костюкова, 46 \\ 1) Belgorod State National Research University, 85, Pobedy St., Belgorod, 308015, Russia \\ 2) Belgorod State Technological University named after V.G. Shukhov, Belgorod, 308012, Russia \\ E-mail: parfenova@bsu.edu.ru, janna-avilova@mail.ru
}

\begin{abstract}
Аннотация
Региональный уровень особенно важен для внедрения инноваций. Особенно в тех государствах, где происходят обширные изменения в экономической; социальной, политической и технологической сферах. На сегодняшний день нет ни одного российского региона, в котором бы функционировала в полном объеме инновационная региональная система. Однако многие из них демонстрируют создание элементов этой системы. В данной статье рассмотрены особенности инновационного развития экономики в Белгородской области, проведен анализ структурных единиц научно-технического комплекса и численности персонала, занятого исследованиями и разработками в регионе. Согласно проведенному анализу исследовательские центры закрываются, в первую очередь, по причине их недофинансирования, при этом, увеличивается количество высших учебных заведений, в которых готовят новые научные кадры. Поэтому на этом этапе развития инновационной деятельности участникам процесса необходима действенная помощь органов государственной власти региона. Были предложены основные направления развития инновационных процессов в регионе для дальнейшего эффективного функционирования всего механизма инновационной региональной системы в целом.
\end{abstract}

\begin{abstract}
The regional level is especially important for innovation. Especially in those states where there are widespread changes in the economic; social, political and technological spheres. Today there is not a single Russian region in which the innovative regional system would fully function. However, many of them demonstrate the creation of elements of this system. This article discusses the features of innovative economic development in the Belgorod region, the analysis of the structural units of the scientific and technical complex and the number of personnel engaged in research and development in the region. According to the analysis, research centers are being closed, first of all, due to their underfunding, while the number of higher education institutions in which new scientific personnel are being trained is increasing. Therefore, at this stage of the development of innovative activity, the participants in this process need effective assistance from state authorities in the region. The main directions of the development of innovative processes in the region were proposed for the further effective functioning of the entire mechanism of the innovative regional system as a whole.
\end{abstract}

Ключевые слова: инновации, инновационная региональная система, инновационное развитие, инновационная политика, инновационные процессы.

Keywords: innovation, innovative regional system, innovative development, innovation policy, innovation processes. 


\section{Введение}

Сегодня цели инновационного развития и научных достижений стали превалировать и подстраивать под себя экономику и политику государства. Инновационные достижения в настоящее время являются важным условием совершенствования общества и экономического роста. В особенности актуальным стало использование инноваций как стратегического инструмента для развития территорий Российской Федерации, которые обладают потенциалами как интеллектуальными, так и промышленными [Бобылев, 2011]. Развитие этих территорий связано не только с применением прогрессивных технологий, но и с их созданием и использованием.

Политика в инновационной сфере является стержнем в социально-экономической политике государства. Особая роль в управлении инновационным развитием принадлежит региональным органам управления. Для ее развития необходимо выполнение двух основных условий. Во-первых, это компетентное региональное управление, включающее разработку стратегии сохранения и развития инновационного потенциала региона, определения функций государственных органов в инновационной сфере и разработка инструментов регулирования инновационной деятельности. Это позволит обеспечить учет мнений всех прямо или косвенно заинтересованных структур и в то же время создать условия для согласованного принятия мер по стимулированию инноваций. И во-вторых, создание системы управления коммерциализацией продуктов НИОКР, опираясь на трудовые ресурсы, обладающие высокой квалификацией, интеллектом и профессионализмом, что будет способствовать увеличению рынков инноваций, финансовых и других видов ресурсов, и в конечном итоге все это позволит улучшить инновационный и инвестиционный климат региона.

\section{Основные результаты исследования}

Осуществляя в своем регионе деятельность по созданию и внедрению инноваций, а также способствуя ее продвижению в объемах своих средств и сил, эти субъекты Российской Федерации, даже с невысоким техническим потенциалом, небольшими ресурсами и финансами, могут решить две стратегические задачи.

Во-первых, инновационная деятельность позволит региону решать существующие проблемы социально-экономического развития с наименьшими затратами и временем на самом современном уровне.

Во-вторых, эта деятельность в будущем приведет к созданию новых рабочих мест в области науки и техники, уменьшению напряженности в социальной сфере, а также поможет сохранить существующие традиции науки и образовательных учреждений благодаря участию талантливых молодых людей в этом процессе, таким образом, станет источником решения огромного перечня социальных и экономических проблем, которые связаны с трудностями и спецификой современного периода [Горфинкель, 2013].

В современных условиях основным подходом в создании программ социальноэкономического развития субъекта Российской Федерации должна стать стратегическая направленность на увеличение его конкурентоспособности, которая может быть только при создании и внедрении инноваций [Лисин, 2016.]. При этом актуальным это должно стать не только в научном мире, но и в практическом.

Кроме того, использование инноваций в качестве стратегического фактора экономического развития субъекта Российской Федерации будет особенно актуально для территорий с достаточно высоким промышленным и интеллектуальным потенциалом. Развитие этих областей возможно не только с использованием высоких технологий, но и с их способностью производить и использовать их [Archibald R.D., Archibald S.C., 2016].

Власти Белгородской области заинтересованы в скорейшем развитии инновационной деятельности в регионе, потому этому вопросу уделяют пристальное внимание. Организационная структура науки в области достаточно разветвлённая. Структурными единицами научно-технического комплекса являются как отдельные исследовательские и 
проектные объединения разных форм собственности, которые предлагают научно обоснованные технические, экономические или технологические решения в своих проектах, так и высшие учебные заведения, выполняющие инновационные разработки [Парфенова, 2015.]. Но при этом в области наблюдается неуклонное снижение числа организаций, осуществляющих исследования и разработки. Так за период с 2000 г. по 2018 г. сокращение произошло на 38,7 \% - с 31 до 19 организаций. Такая ситуация происходит в большей степени за счет сокращения числа научно-исследовательских организаций, конструкторских и технологических организаций, а также проектных и проектно-изыскательских организаций. Это приводит к уменьшению научных исследований. Кроме того, конструкторскоисследовательские компании, занимающиеся прикладными исследованиями, прекратили свою деятельность, что привело к еще большей разобщенности и потере связи между наукой и производством. Положительная динамика наблюдается только в разрезе увеличения высших учебных заведений. Перспективы развития научной и научно-технической деятельности в высшей школе связаны с синтезом уровня качества средств производства, в основе которых лежат изобретения и ноу-хау, а так же людей, обладающих знанием и умением наиболее эффективно применять современную технику и технологию (табл. 1) [Белгородская область..., 2018].

Таблица 1

Table 1

Организации Белгородской области, выполняющие исследования и разработки за 2000-2018гг. (ед.)

Organizations of the Belgorod region, carrying out research and development for 2000-2018. (unit)

\begin{tabular}{|l|l|l|l|l|l|}
\hline & \multicolumn{3}{|c|}{ Года } & \multicolumn{2}{l|}{ Темпы роста \% } \\
\hline Организации & 2000 & 2005 & 2018 & $\begin{array}{l}2005 / \\
2000\end{array}$ & $\begin{array}{l}2018 / \\
2000\end{array}$ \\
\hline Всего & 31 & 23 & 19 & 74,2 & 61,3 \\
\hline в том числе: & & & & & \\
\hline научно-исследовательские & 12 & 15 & 8 & 125,0 & 66,7 \\
\hline конструкторские и технологические & 7 & - & - & - & - \\
\hline проектные и проектно-изыскательские & 4 & 2 & - & 50,0 & - \\
\hline высшие учебные заведения & 4 & 4 & 6 & 100,0 & 150,0 \\
\hline прочие & 4 & 2 & 5 & 50,0 & 125,0 \\
\hline
\end{tabular}

Анализ организаций Белгородской области, участвующих в изобретениях и исследованиях за период 2000-2018 гг., показал, что происходит ежегодное их уменьшение. Такое явление, в первую очередь, связано с тем, что сократилось финансирование научных исследований крупными предприятиями региона. Это способствовало тому, что исследовательские центры вынуждены были закрыться.

С другой стороны, учитывая тот факт, что в странах с развитой рыночной экономикой организация высших школ является доминирующей, поэтому наметившаяся положительная тенденция в сфере образования и науки будет направлена на активизацию научноисследовательской деятельности в высших учебных заведениях.

Такая ситуация показывает, что инновационная политика в регионе еще недостаточно сформирована, и поэтому необходимо дальнейшее развитие. [Зекох, Мартыненко, 2015.]. При этом надо отметить, что область сделала немало для создания инфраструктуры инновационной деятельности. Так, принят закон и план развития по инновационной деятельности, созданы фонд поддержки предпринимательства и центр трансфера технологий. Однако существующие научно-исследовательские организации в Белгородской области не могут обеспечить инновационный сектор экономики необходимой поддержкой. 
Снижение количества научных учреждений не единственная проблема в инновационном пути развития региона. Такая же ситуация наблюдается и с численностью работников, занятых исследованиями и разработками в этой области.

Конечно, уменьшение научно-исследовательских организаций может означать их слияние, при этом штатная численность должна увеличиваться [Казакова и др., 2009]. Но это ложное суждение, так как, начиная с 2005 года, сокращается средняя численность научноисследовательских сотрудников в расчете на одну организацию.

Так, за анализируемый период общая численность персонала, занятого исследованиями и разработками, сократилась. За пять лет, с 2000 г. по 2005 г., снижение произошло на $66 \%$, после этого ситуация стала постепенно меняться, и к 2018 г. темп прироста составил 33,2\%. Анализ в разрезе по категориям персонала показал его сокращение на протяжении анализируемого периода. Исключение составили исследователи и прочий персонал, численность которых за анализируемый период менялась скачкообразно: в первые годы происходило сокращение более чем на $67 \%$ по этим категориям, затем наметились положительные тенденции, и к 2018 году темп роста составил 87,2 \% и 3,3 \% соответственно (табл. 2) [Белгородская область..., 2018].

Таблица 2

Table 2

Численность персонала, занятого исследованиями и разработками в Белгородской области за 2000-2018 гг. (чел.)

The number of personnel engaged in research and development in the Belgorod region for 2000-2018 (people)

\begin{tabular}{|l|l|l|l|l|l|}
\hline \multirow{2}{*}{$\begin{array}{l}\text { Численность } \\
\text { персонала }\end{array}$} & \multicolumn{3}{|c|}{ Года } & \multicolumn{2}{c|}{ Темпы роста \% } \\
\hline Всего & 2000 & 2005 & 2018 & $2005 / 2000$ & $2018 / 2005$ \\
\hline в том числе: & 1953 & 1289 & 1717 & 66,0 & 133,2 \\
\hline исследователи & 984 & & & & \\
\hline техники & 268 & 184 & 1247 & 67,7 & 187,2 \\
\hline $\begin{array}{l}\text { Вспомогательный } \\
\text { персонал }\end{array}$ & 342 & 197 & 76 & 68,6 & 53,8 \\
\hline Прочий персонал & 359 & 242 & 250 & 67,4 & 97,5 \\
\hline
\end{tabular}

Анализ показал, что общее число исследователей имеет тенденцию к сокращению и, прежде всего, это происходит за счет техников и вспомогательного персонала. Положительным моментом является увеличение численности исследователей за последнее время. На это указывает и тот факт, что увеличилось количество высших учебных заведений, в которых подготавливают новые научные кадры.

При этом надо признать, что имея достаточные ресурсы для разработки новых идей и технологий, регион в полной мере не использует свой потенциал. Так, крупные белгородские предприятия, имеющие значительные финансовые средства для освоения перспективных знаний и технологий нового поколения, не внедряют у себя инновационные научные идеи. В результате эти идеи остаются невостребованными. В конечном итоге, замедляется прогрессивное развитие всех сфер экономики и общества в целом в регионе [Моттаева, 2014].

Bсе экономические субъекты, чтобы осуществлять эффективную инновационную работу, будут заинтересованы в государственных органах, которые помогут им выстроить действенные управленческие решения во всех звеньях цепочки, от фундаментальных исследований, деятельности по разработке инноваций и опытного производства до серийного производства и выхода на рынок [Маскайкин, 2009]. Однако очевидно, что государственные власти региона не могут вкладывать огромные денежные средства по всем звеньям цепочки: от фундаментальных исследований до реализации на рынке. Тем не менее, чтобы создать в производственном секторе условия для разработки новых идей и воплотить эти 
инновационные идеи в продукт, который мог бы быть востребованым на рынке, это должно быть главной задачей органов государственной власти [Samonas M., 2015].

В последние годы появились разнообразные мероприятия, которые направлены на привлечение большего количества российского бизнеса к участию в инновационной деятельности. Так, ежегодными стали такие мероприятия, как Инновационный форум «Молодежь и стратегии развития территорий» (г. Новосибирск), Международный форум по нанотехнологиям (г. Москва); Всероссийский молодежный инновационный конвент (г. Москва); Молодежный образовательный инновационный форум «Селигер» и другие.

Кроме того, государство, даже в непростой международной ситуации, стало больше оказывать поддержку российскому бизнесу, создавая различные фонды содействия инновационному пути развития экономики регионов и страны в целом. Так, Указом Президента РФ от 30 июля 2008 г. №1144 «О премии Президента Российской Федерации в области науки и инноваций для молодых ученых» учреждены ежегодные премии молодым ученым по 2,5 млн руб. каждая [Сутугина, Склярова, 2016].

Однако на практике существуют определенные трудности, которые сдерживают эффективное развитие инновационной деятельности в регионах, и в частности, в Белгородской области:

1. Малые инновационные предприятия, которые создаются в технопарках и центрах, надолго остаются там. Это приводит к тому, что у этих предприятий перестает увеличиваться объем производства, а кроме того, в этих центрах и технопарках нет свободных площадей для появления новых инновационных предприятий. Поэтому только инновационнотехнологический центр и технопарк можно считать объектами инновационной инфраструктуры, которые формируют благоприятные условия для создания инновационных производств в научно-технической сфере, обладают оснащенной и экспериментальной базой и высокой концентрацией квалифицированных кадров.

2. Современное производство немыслимо без применения передовых технологий. Они играют решающую роль в его развитии, а также способствуют процветанию бизнеса и обеспечению его конкурентоспособности. Однако в силу очень большой стоимости многие инновационные предприятия отказываются от внедрения в свое производство новых технологий, что в конечном итоге приводит к тому, что замедляется темп роста производства и снижается конкурентоспособность бизнеса [Кошелева, 2015].

3. Одной из проблем является старение кадров, которые являются носителями ключевых технологий. Без прихода молодых квалифицированных специалистов передовые применяемые технологии могут быть частично утеряны.

Учитывая сложившиеся проблемы, необходима качественная трансформация в развитии региональной политики, которая бы изменила подход к формированию и развитию инновационной деятельности, обеспечив оптимальные условия для протекания инновационных процессов в области [Курбанкулиев, 2016]. В связи с этим, можно сформулировать основные направления развития инновационных процессов в регионе, которые должны быть реализованы органами государственной власти Белгородской области.

Первую проблему можно решить, установив лимит времени для небольшого инновационного предприятия в составе технопарка.

Вторую сложившуюся ситуацию можно решить благодаря совместной эксплуатации высококачественного оборудования в центрах и технопарках.

Третья проблема может быть решена путем подготовки профессиональных кадров квалифицированным специалистам приступать к работе через 6-10 лет с учетом подготовки в высшем заведении базового образования и приобретения практических навыков.

\section{Основные выводы}

Координирование инновационных процессов должно осуществляться региональными администрациями. В этом контексте основное направление региональной политики организовать интеграцию ресурсов в ключевые направления, разработать стратегии 
сотрудничества между стратегическими партнерами в рамках новой модели развития: администрация, компании и общественные институты [Шамина, 2015]. Таким образом, при государственной поддержке создания новых технологий и новых разработок в регионе наиболее важными являются институционные и правовые рамки для поддержки и стимулирования финансовых партнеров, инновационных компании в реализации структурных преобразований экономики субъекта Российской Федерации [Gassmann Oliver, 2016].

Таким образом, исходя из вышеизложенного следует, что в современных условиях инновационные процессы необходимо рассматривать как фактор стратегического роста экономики любого субъекта Российской Федерации [Щитова, 2014]. Государственные органы регионов должны активно способствовать внедрению инновационных разработок в само производство, что, в свою очередь, позволит населению региона пользоваться товарами и услугами самого высокого качества, и, в конечном счёте, обеспечат повышение уровня жизни российских граждан.

\section{Список литературы}

1. Белгородская область в цифрах. 2018. Краткий статистический сборник, Белгородстат, 300.

2. Бобылев Г.В., Кузнецов А.В., Горбачева Н.В. 2011. Условия и факторы реализации инновационного потенциала региона. Регион: экономика и социология. 1: 113-126.

3. Галушко М.В., Чахеев А.А. 2019. Инновационное развитие регионов России с учетом их особенностей и направленностей экономик. В кн.: Актуальные вопросы экономических наук и современного менеджмента. Материалы XXIII международной научно-практической конференции. 6 (16). Новосибирск, Изд-во СибАК: 52-66.

4. Горфинкель В.Я. 2013. Инновационное предпринимательство. Москва: Гриф МО, 523.

5. Зекох А.А., Мартыненко Е.Д. 2015. Функциональное содержание механизма формирования инновационной региональной политики. Новые технологии. 1: 118-121.

6. Казакова Н.А., Наседкина Т.И., Французова И.И. 2009. Анализ факторов формирования инновационной модели развития региональной экономики: российский и мировой опыт. Менеджмент в России и за рубежом. 3: 25-29.

7. Кошелева Т.Н. 2015. Инновационная политика как фактор развития малого предпринимательства. Экономика и управление. 4 (90): 75-78.

8. Курбанкулиев, Б.Р. 2016. К вопросу о механизмах снижения высоких предпринимательских рисков в сфере инновационной деятельности. Новая наука: Проблемы и перспективы. 4-1: 133-134.

9. Лисин Б.К. 2016. Межгосударственное социально-экономическое исследование инновационного потенциала. Инновации. 7: $62-68$.

10.Маскайкин Е.П. 2009. Понятие, содержание и модель региональной инновационной системы. Креативная экономика. 8 (32): 66-74.

11.Моттаева А.Б. 2014. Инновационные риски в предпринимательстве. Общество. Государство. Право. 2: 26-32.

12.Парфенова Е.Н. 2015. Развитие элементов инновационной инфраструктуры региона. Научные ведомости Белгородского государственного университета. Экономика Информатика. 19 (216) вып. 36/1: 14-20.

13.Сутугина М.В., Склярова Е.Е. 2016. Инновационный потенциал регионов России как фактор экономического роста. Научно-методический электронный журнал «Концепт». 12: 66-71. URL: http://e-koncept.ru/2016/46214.htm (дата обращения: 10 ноября 2019).

14.Шамина М.К. 2015. Оценка риска инновационного процесса. Экономика и экологический менеджмент. 1: 3-25.

15.Щитова А.Н. 2014. Инновационная политика экономики России. В кн.: Инновационная экономика. Материалы международной научной конференции материалы междунар. науч. конф. (Казань, октябрь 2014 г.). Казань, Изд-во Бук : 6-11.

16. Archibald R.D., Archibald S.C. 2016. Leading and managing innovation: what every executive team must know about project, program and portfolio management PDF. 2nd ed. CRC Press, $216 \mathrm{p}$.

17.Gassmann Oliver, Frankenberger Karolin, Sauer Roman. 2016. Exploring the Field of Business Model Innovation: New Theoretical Perspectives PDF. Palgrave Macmillan, 126 p.

18. Samonas M. 2015. Financial Forecasting, Analysis and Modelling: A Framework for Long-Term Forecasting. N.-Y.: Wiley, 232p. 


\section{References}

1. Belgorodskaya oblast' $\mathrm{v}$ tsifrakh [Belgorod region in numbers]. 2018. Kratkiy statisticheskiy sbornik, Belgorodstat, 300.

2. Bobylev G.V., Kuznetsov A.V., Gorbacheva N.V. 2011. Usloviya i faktory realizatsii innovatsionnogo potentsiala regiona [Conditions and factors for the implementation of the innovative potential of the region]. Region: ekonomika i sotsiologiya. 1: 113-126.

3. Galushko M.V., Chakheev A.A. 2019. Innovatsionnoe razvitie regionov Rossii s uchetom ikh osobennostey i napravlennostey ekonomik [Innovative development of the Russian regions, taking into account their characteristics and economies]. V kn.: Aktual'nye voprosy ekonomicheskikh nauk i sovremennogo menedzhmenta [Actual issues of economic sciences and modern management]. Materialy XXIII mezhdunarodnoy nauchno-prakticheskoy konferentsii. 6(16). Novosibirsk, Izd-vo SibAK: 52-66.

4. Gorfinkel', V.Ya. 2013. Innovatsionnoe predprinimatel'stvo [Innovative entrepreneurship]. Moskva: Grif MO, 523.

5. Zekokh A.A., Martynenko E.D. 2015. Funktsional'noe soderzhanie mekhanizma formirovaniya innovatsionnoy regional'noy politiki [Functional content of the mechanism for the formation of innovative regional policy]. Novye tekhnologii. 1: 118-121.

6. Kazakova N.A., Nasedkina T.I., Frantsuzova I.I. 2009. Analiz faktorov formirovaniya innovatsionnoy modeli razvitiya regional'noy ekonomiki: rossiyskiy i mirovoy opyt [Analysis of the factors of formation of an innovative model for the development of a regional economy: Russian and world experience]. Menedzhment v Rossii i za rubezhom. 3: 25-29.

7. Kosheleva T.N. 2015. Innovatsionnaya politika kak faktor razvitiya malogo predprinimatel'stva [Innovation policy as a factor in the development of small business]. Ekonomika i upravlenie. 4 (90): 75-78.

8. Kurbankuliev, B.R. 2016. K voprosu o mekhanizmakh snizheniya vysokikh predprinimatel'skikh riskov v sfere innovatsionnoy deyatel'nosti [On the issue of mechanisms to reduce high entrepreneurial risks in the field of innovation]. Novaya nauka: Problemy i perspektivy. 4-1: 133-134.

9. Lisin B.K. 2016. Mezhgosudarstvennoe sotsial'no-ekonomicheskoe issledovanie innovatsionnogo potentsiala [Interstate Social and Economic Research on Innovation Potential]. Innovatsii. 7: 62-68.

10. Maskaykin E.P. 2009. Ponyatie, soderzhanie i model' regional'noy innovatsionnoy sistemy [The concept, content and model of a regional innovation system]. Kreativnaya ekonomika. 8 (32): 66-74.

11. Mottaeva A.B. 2014. Innovatsionnye riski $\mathrm{v}$ predprinimatel'stve [Innovation risks in entrepreneurship]. Obshchestvo. Gosudarstvo. Pravo. 2: 26-32.

12. Parfenova E.N. 2015. Razvitie elementov innovatsionnoy infrastruktury regiona [Development of elements of the innovation infrastructure of the region]. Nauchnye vedomosti Belgorodskogo gosudarstvennogo universiteta. Ekonomika Informatika. 19 (216) vyp.36/1: 14-20.

13. Sutugina M.V., Sklyarova E.E. 2016. Innovatsionnyy potentsial regionov Rossii kak faktor ekonomicheskogo rosta [The innovative potential of Russian regions as a factor of economic growth]. Nauchno-metodicheskiy elektronnyy zhurnal «Kontsept». 12: 66-71. URL: http://e-koncept.ru/2016/46214. htm (data obrashcheniya: 10 noyabrya 2019).

14. Shamina M.K. 2015. Otsenka riska innovatsionnogo protsessa. Ekonomika i ekologicheskiy menedzhment. 1: 3-25.

15. Shchitova A.N. 2014. Innovatsionnaya politika ekonomiki Rossii [innovation process risk assessment]. V kn.: Innovatsionnaya ekonomika [Innovative economy]. Materialy mezhdunarodnoy nauchnoy konferentsii materialy mezhdunar. nauch. konf. (Kazan', oktyabr' 2014 g.). Kazan', Izd-vo Buk : 6-11.

16. Archibald R.D., Archibald S.C. Leading and managing innovation: what every executive team must know about project, program and portfolio management PDF. 2nd ed. CRC Press, 2016. 216 p.

17. Gassmann Oliver, Frankenberger Karolin, Sauer Roman. Exploring the Field of Business Model Innovation: New Theoretical Perspectives PDF. Palgrave Macmillan, 2016. 126 p.

18. Samonas M. Financial Forecasting, Analysis and Modelling: A Framework for Long-Term Forecasting. N.-Y.: Wiley, 2015. 232p.

\section{Ссылка для цитирования статьи For citation}

Парфенова Е.Н., Авилова Ж.Н. 2020. Формирование условий инновационного развития экономики региона. Экономика. Информатика. 47 (2): 288-294. DOI: 10.18413/2687-0932-2020-47-2-288-294.

Parfenova E.N., Avilova Zh.N. 2020. Formation of the conditions of innovative development of the economy of the region. Economics. Information technologies. 47 (2): 288-294 (in Russian). DOI: 10.18413/2687-0932-2020-47-2-288-294. 